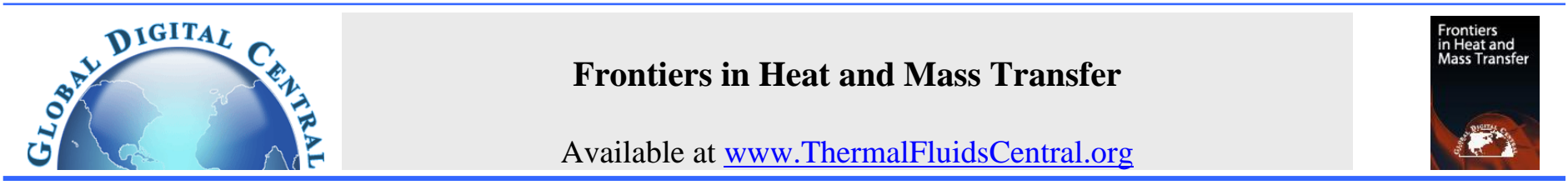

\title{
NUMERICAL SOLUTION ON NON-UNIFORM MESH OF DARCY-BRINKMAN-FORCHHEIMER MODEL FOR TRANSIENT CONVECTIVE HEAT TRANSFER OVER FLAT PLATE IN SATURATED POROUS MEDIUM
}

\author{
Elyazid Flilihi, Mohammed Sriti, Driss Achemlal \\ Sidi Mohamed Ben Abdellah University, Polydisciplinary Faculty of Taza, Engineering Sciences Laboratory, BP.1223, Taza, Morocco
}

\begin{abstract}
A numerical investigation is performed to analyze the transient laminar free convection over an isothermal inclined plate embedded in a saturated porous medium with the viscous dissipation effects. The flow in the porous medium is modeled with the Darcy-Brinkman- Forchheimer model, taking into account the convective term. The dimensionless nonlinear partial differential equations are solved numerically using an explicit finite difference method. The effects of different parameters: $\left(1 \leq R e \leq 10 ; 10^{-2} \leq D a \leq 10 ; 0 \leq G r \leq 50 ; 0 \leq F r \leq 3 ; 0 \leq E c \leq 1\right.$; $0 \leq \phi \leq 90^{\circ}$ and $\operatorname{Pr}=0.71$ ) that enter into the problem on the dimensionless streamlines of the velocity field, the isothermal lines distributions and the local Nusselt number are examined. Also, the physical aspects of the problem are discussed in details. It is found that the viscous dissipation and the inertial forces have a significant effect on the temperature field whereas the wall heat transfer rate is optimal for the vertical position of the plate.
\end{abstract}

Keywords: Free convection, unsteady flow, Darcy-Brinkman-Forchheimer model, porous medium, finite difference method.

\section{INTRODUCTION}

Studies of thermal convection in porous media have generated increasing interest during the past few decades because of their importance in many engineering applications such as the infiltration of water in aquifers, the use of geothermal energy, the extraction of oil and gas through the soil, the drying of the food products, the storage of radioactive, the biological systems, etc. The growing volume of work devoted to this area is amply documented in the recent excellent reviews by Vafai (2005), Nield and Bejan (2017) and Nield and Simmons (2018).

Numerous studies of such flows have been reported in the past several decades using both Darcian and non-Darcian models for the porous medium. The Darcy law is limited to slow flows. On the other hand, when the Reynolds number is greater than order of unity, or, for high velocity flow situations, Darcy's law is inapplicable because it does not account the effect of solid boundary, inertia forces. These missing effects are very significant in most practical situations such as fluid flow in geothermal reservoirs, separation processes in chemical industries, thermal insulation, petroleum reservoir, and so on. These effects are incorporated by using the general flow known as Brinkman-Forchheimer extended Darcy model (Chen and Chen, 1990; Aldoss et al., 1996; Khanafer and Chamkha, 1999). The Brinkman's extension, which includes a viscous shear stress term in the momentum equation, has been used to account for the boundary effects. The inertial effects can be modelled through the addition of a quadratic term in velocity, which is known as Forch- heimer's extension. Therefore, the recent studies have been focused on the importance of convective heat transport phenomenon in non-Darcian porous media.

Several studies were carried out to analyse the transient free convection heat transfer in saturated porous media by a Newtonian fluid, under Darcy's laws, or, non-Darcy's law, based on the Darcy- Brinkmanforchheimer Formulation. Raptis et al. (1987) have examined the unsteady free convective flow through a porous medium adjacent to a semiinfinite vertical plate using finite difference scheme. These authors found that, the velocity increases with permeability parameter, whereas the temperature decreases with it. After, Pop and Herwig (1990) studied transient mass transfer from an isothermal vertical flat plate embedded in saturated porous medium. Also, Ganesan and Palani (2004) have studied the numerical solution of transient free convection MHD flow of an incompressible viscous fluid flow past a semi-infinite inclined plate with variable surface heat and mass flux. The set of governing equations are solved by using an implicit finite difference scheme. Later, the effects of viscous dissipation on unsteady free convection in a fluid past a vertical and an inclined plate immersed in a porous medium have been discussed by (El-Amin and Ebrahiem, 2006; Udin and Kumar, 2010). In these works, the basic equations of the boundary layer are transformed into a non-dimensional form and reduced to nonlinear systems of partial differential equations, and solved numerically by using an explicit finite

${ }^{\dagger}$ Corresponding author. Email: elyazid_flilihi@yahoo.fr 
difference method. Furthermore, Vasu et al. (2011) have investigated the effects of radiation and mass transfer on transient free convection flow of a dissipative fluid past semi-infinite vertical plate with uniform heat and mass flux. These authors found that the greater viscous dissipative heat causes rise in the temperature as well as the velocity. Similarly, the effects of radiation and viscous dissipation on unsteady free convective flow past a moving vertical porous plate embedded in a porous medium was analyzed by Das et al. (2013).

Recently, Mohiddin et al. (2014) have considered a numerical study of buoyancy-driven unsteady natural convection boundary layer flow past a vertical cone embedded in a non-Darcian isotropic porous media with transverse magnetic field applied normal to the surface. The results obtained show that an increase in the Forchheimer inertial drag parameter local Nusselt number. The works of Achemlal et al. (2014); Achemlal and Sriti (2015) used the finite difference method for solving steady free convection flow based on the Darcy's laws over an isothermal vertical plate in a saturated porous medium and compared the results obtained with those found by the similarity approach. Very recently, Islam et al. (2015) studied mass transfer flow through an inclined plate with porous medium. In this numerical investigation, the explicit finite difference method has used to solve the dimensionless system of equations. Mondal et al. (2016) have analyzed the unsteady free convective flow along a vertical porous plate with variable viscosity and thermal conductivity, with viscous dissipation and heat generation. In this work, the problem is resolved numerically using an explicit finite difference method. The obtained results show that the temperature profile increases for the increasing of thermal conductivity parameter, Eckert number and heat generation parameter. Also, Flilihi et al. (2017) investigated the variable heat source and wall radiation effects on boundary layer convection from an inclined plate in non-Darcian porous medium.

The present paper is an extension of the works of Flilihi et al. (2017, 2019) to an unsteady convective boundary layer flow past an inclined plate in a non darcian porous medium in the presence of the viscous dissipation effects using the Darcy-Brinkman-Forchheimer model, which includes the effects of boundary and inertia forces taking into account the convective term. This study finds applications in the fields of petroleum engineering, geothermal energy, etc...

\section{PHYSICAL MODEL AND GOVERNING EQUATIONS}

Consider a two dimensional transient laminar free convection flow of a fluid over an isothermal inclined plate embedded in a non Darcian porous medium. Initially, it is assumed that the plate and the fluid are at the temperature $T_{\infty}$. At $t^{\prime}>0$, the temperature of the plate is raised to $T_{w}$, which is then maintained constant. The temperature of the fluid away from the plate is $T_{\infty}$. The physical model and coordinate system are shown in Fig. 1.

The Darcy-Brinkman-Forchheimer model is used to describe the flow in the porous medium. Under the Boussinesq and boundary layer approximations, the governing equations are: leads to increase slightly the temperature, but reduces both velocity and

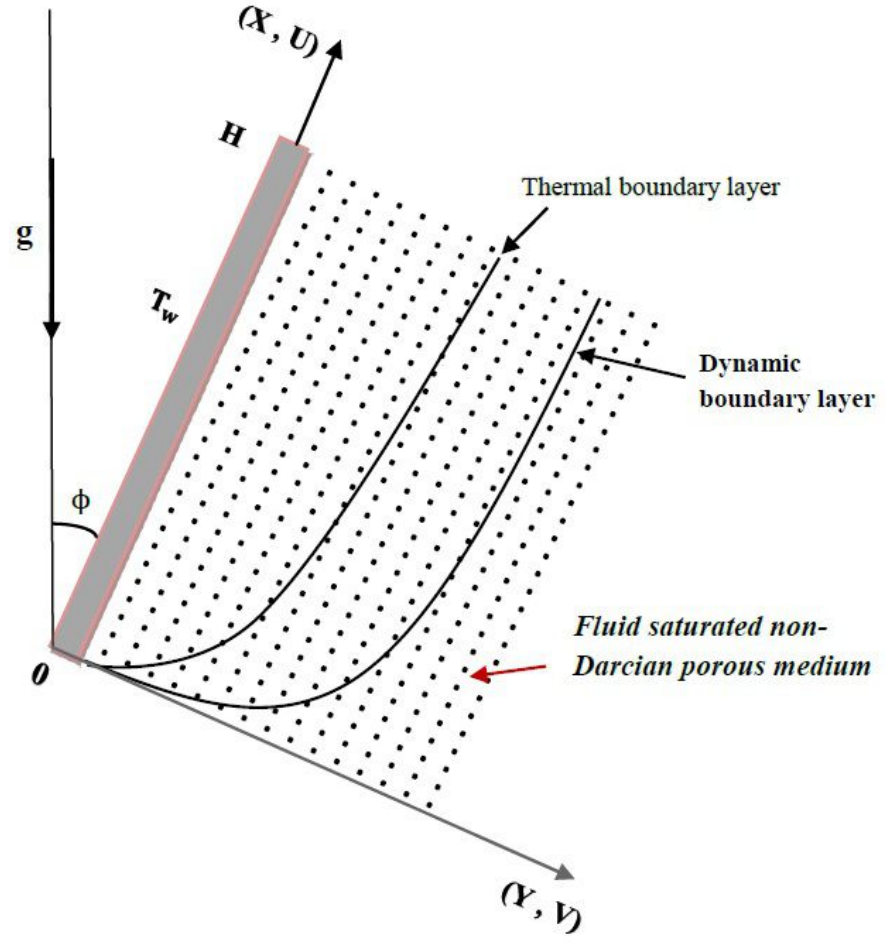

Fig. 1 Physical model and coordinate system.

The initial and boundary conditions are:

$$
\begin{aligned}
& t^{\prime}=0: u=v=0, \quad T=T_{\infty} \quad \text { for all } x \text { and } y \\
& t^{\prime}>0:\left\{\begin{array}{l}
u=v=0, T=T_{\infty} \text { at } x=0 \\
u=v=0, T=T_{w} \text { at } y=0, x>0 \\
u=0, T=T_{\infty} \text { at } y \rightarrow \infty, \quad x>0
\end{array}\right.
\end{aligned}
$$

where $x$ and $y$ are the Cartesian coordinates and $t^{\prime}$ represents time. $\mathrm{u}$ and $\mathrm{v}$ are, respectively, the velocity components along the $\mathrm{x}$ - and $\mathrm{y}$-axes, $T$ is the fluid temperature. The constants $\mu, \nu, K, \alpha$, g and $\rho$ are, respectively, fluid viscosity, kinematic viscosity, permeability of porous medium, thermal diffusivity, gravitational acceleration, and density. $C p, \beta, \varepsilon, F$ are, respectively, the specific heat at constant pressure, the coefficient of thermal expansion, the porosity of porous medium and the empirical constant.

\section{DIMENSIONLESS GOVERNING EQUATIONS}

The use of dimensionless variables allows one to express the reality of physical phenomena independently of the measurement systems. For this, it is often convenient to write the governing equations in dimensionless form before its numerical resolution. The nondimensionalization was carried out according to the following definitions (El-Amin and Ebrahiem, 2006; Udin and Kumar, 2010; Achemlal et al., 2014):

$\left\{\begin{array}{l}\frac{\partial u}{\partial x}+\frac{\partial v}{\partial y}=0 \\ \frac{\partial u}{\partial t^{\prime}}+u \frac{\partial u}{\partial x}+v \frac{\partial u}{\partial y}=\nu \frac{\partial^{2} u}{\partial y^{2}}+g \beta\left(T-T_{\infty}\right) \cos \phi-\frac{\nu \varepsilon}{K} u-\frac{F \varepsilon^{2}}{K^{1 / 2}}|u| u \\ \frac{\partial T}{\partial t^{\prime}}+u \frac{\partial T}{\partial x}+v \frac{\partial T}{\partial y}=\alpha \frac{\partial^{2} T}{\partial y^{2}}+\frac{\mu}{\rho C_{p}}\left(\frac{\partial u}{\partial y}\right)^{2}\end{array}\right.$

$$
\left\{\begin{array}{l}
(X, Y)=\frac{(x, y)}{H}, \quad(U, V)=\frac{(u, v)}{U_{r}}, \quad \theta=\frac{T-T_{\infty}}{T_{w}-T_{\infty}} \\
t=\frac{U_{r} t^{\prime}}{H} \quad \text { with } U_{r}=\frac{\nu}{H}
\end{array}\right.
$$

here $U_{r}$ is a reference velocity, and $H$ is the height of the plate. In terms of these variables, and After substitution and development, the 
system of equations (1) becomes:

$$
\left\{\begin{array}{l}
\frac{\partial U}{\partial X}+\frac{\partial V}{\partial Y}=0 \\
\frac{\partial U}{\partial t}+U \frac{\partial U}{\partial X}+V \frac{\partial U}{\partial Y}=\frac{\partial^{2} U}{\partial Y^{2}}+G r \theta \cos \phi-\frac{1}{D a} U-\frac{F r}{D a}|U| U \\
\frac{\partial \theta}{\partial t}+U \frac{\partial \theta}{\partial X}+V \frac{\partial \theta}{\partial Y}=\frac{1}{\operatorname{Pr} \cdot \operatorname{Re}} \frac{\partial^{2} \theta}{\partial Y^{2}}+E c\left(\frac{\partial U}{\partial Y}\right)^{2}
\end{array}\right.
$$

Here $G r=\frac{g \beta\left(T_{w}-T_{\infty}\right) H}{U_{r}^{2}}$ is the Grashof number, $D a=\frac{K}{H^{2} \varepsilon}$ is the Darcy number, $F r=\frac{F \varepsilon K^{1 / 2}}{H}$ is the inertia coefficient, $\operatorname{Pr}=\frac{\mu}{\rho \alpha}$ is the Prandtl number, $R e=\frac{\rho H U_{r}}{\mu}$ is the Reynolds number and $E c=$ $\frac{U_{r}}{C_{p}\left(T_{w}-T_{\infty}\right)}$ is the Echert number.

The transformed initial and boundary conditions for equations (3) are now given by:

$$
\begin{gathered}
t=0: U=V=\theta=0, \quad \text { for all } X \quad \text { and } Y . \\
t>0:\left\{\begin{array}{l}
U=V=\theta=0, \quad \text { at } X=0 \\
U=V=0, \theta=1 \quad \text { at } Y=0, X>0 \\
U=0, \theta=0 \text { at } Y \rightarrow \infty, \quad X>0
\end{array}\right.
\end{gathered}
$$

\section{SOLUTION METHOD AND NON-UNIFORM GRID}

The system of non-linear equations (4) subject to the initial and boundary conditions (5) are solved numerically for the velocity and temperature using the explicit finite differences method, as explained by Carnahan et al. (1969). For this study, we consider a plate of height $X_{\max }=$ 100 and regarded $Y_{\max }=35$ which corresponds to $Y=\infty$, where $X$ direction is taken along the plate and $Y$ direction is taken normal to it. Subscripts $i$ and $j$ will be used to represent nodes in $X$ and $Y$ directions, respectively.

Physically, the thickness of the boundary layer is much smaller than any characteristic length defined in the streamwise direction. Therefore, the changes in physical properties in the direction parallel to the plate are small compared to the corresponding changes in perpendicular to the plate. Thus, grids in the $\mathrm{Y}$ direction should be much finer close to the plate and spaced elsewhere. Figure 2 shows the grid used in this study for numerical solution, making the grid much finer close to the plate for a better appreciation of the formation of the boundary layer.

A variable grid size in the Y-axis is calculated with Eq.(7).

$$
\begin{aligned}
& Y(j)=Y_{\max } \cdot\left[\frac{e^{\alpha_{y}(j-N)}-A_{y}}{1-A_{y}}\right] \\
& \triangle Y(j-1)=Y(j)-Y(j-1)
\end{aligned}
$$

with $j=2, \ldots, N$ and $A_{y}=e^{\alpha_{y}(1-N)}$, where $\alpha_{y}$ is the distribution coefficient in the $\mathrm{Y}$-axis, generally between 0 and $1 . \mathrm{N}$ is the number of nodes contained on Y direction.

\section{NUMERICAL FORMULATION AND SOLUTION}

The unsteady non-linear coupled equations (4) subject to the initial and boundary conditions (5) are solved by using an explicit finite-difference scheme. The set of approximate finite difference equations corresponding

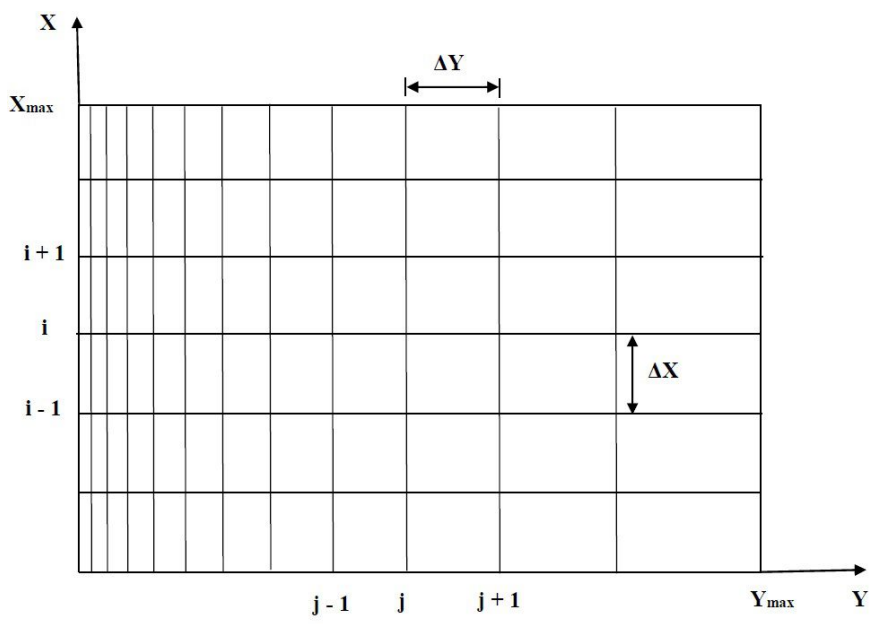

Fig. 2 Grid used in the numerical solution.

to system of equations (4) are:

$$
\left\{\begin{array}{l}
\frac{U_{i, j}^{k+1}-U_{i-1, j}^{k+1}}{\triangle X}-\frac{V_{i, j}^{k+1}-V_{i-1, j}^{k+1}}{\triangle Y(j)}=0 \\
\frac{U_{i, j}^{k+1}-U_{i, j}^{k}}{\triangle t}+U_{i, j}^{k} \frac{U_{i, j}^{k}-U_{i-1, j}^{k}}{\triangle X}+V_{i, j}^{k} \frac{U_{i, j}^{k}-U_{i-1, j}^{k}}{\triangle Y(j)}=G r \theta_{i, j}^{k+1} \\
\quad+\frac{U_{i, j+1}^{k}-2 U_{i, j}^{k}+U_{i, j-1}^{k}}{(\triangle Y(j))^{2}}-\frac{1}{D a} U_{i, j}^{k}-\frac{F r}{D a}\left|U_{i, j}^{k}\right| U_{i, j}^{k} \\
\frac{\theta_{i, j}^{k+1}-\theta_{i, j}^{k}}{\triangle t}+U_{i, j}^{k} \frac{\theta_{i, j}^{k}-\theta_{i-1, j}^{k}}{\triangle X}+V_{i, j}^{k} \frac{\theta_{i, j+1}^{k}-\theta_{i, j}^{k}}{\triangle Y(j)}= \\
\frac{1}{\operatorname{Pr} . \operatorname{Re}} \frac{\theta_{i, j+1}^{k}-2 \theta_{i, j}^{k}+\theta_{i, j-1}^{k}}{(\triangle Y(j))^{2}}+E c \cdot\left(\frac{U_{i, j+1}^{k}-U_{i, j}^{k}}{\triangle Y(j)}\right)^{2}
\end{array}\right.
$$

The coefficients $U_{i, j}$ and $V_{i, j}$ are treated as constants, during any one time-step. Then, at the end of any time step $\Delta t$, the new velocity components $U^{k+1}$ and $V^{k+1}$, and the new temperature $\theta^{k+1}$ at all interior grid points may be obtained by successive applications of system of equations (8). The region of integration is considered as a rectangle with sides $\mathrm{X}, X_{\max }=100$ and $\mathrm{Y}, Y_{\max }=35$. After performing few tests on sets of mesh sizes to access grid independence taking account a variable grid size in the Y-axis calculated with Eq.(7), the time and spatial step sizes $\Delta t=0.05$ and $\Delta X=2$ were found to give accurate results.

\section{LOCAL NUSSELT NUMBER}

The primary physical quantity of interest is the local Nusselt number $N u$. From the definition of the local surface heat flux:

$$
q_{w}=-\left.k_{e} \frac{\partial T}{\partial y}\right|_{y=0}=-\left.\frac{k_{e}\left(T_{w}-T_{\infty}\right)}{L} \frac{\partial \theta}{\partial Y}\right|_{Y=0}
$$

where $k_{e}$ is the effective thermal conductivity of the saturated porous medium. Therefore the local Nusselt number is given by:

$$
N u=\frac{q_{w}}{T_{w}-T_{\infty}} \frac{L}{k_{e}}=-\left.\frac{\partial \theta}{\partial Y}\right|_{Y=0}
$$

\section{RESULTS AND DISCUSSION}

A numerical investigation has been made for an unsteady thermal convection flow along an isothermal inclined plate embedded in non-Darcian porous medium, using the Darcy-Brinkman-Forchheimer model, taking 
into account the convective term. In this study, we have analyzed the effects of the time $t$, inclination angle $\phi$, Darcy number $D a$, Reynolds number $R e$, Grashof number $\mathrm{Gr}$, Forchheimer number $\mathrm{Fr}$ and Echert number $E c$ on the thermal, dynamic and the wall heat transfer rate profiles.

To assess the accuracy of our results, the comparisons are made with Udin and Kumar (2010) results in term of local Nusselt number for Eckert number $E c=0.0$ at $\mathrm{Gr}=1, \mathrm{Re}=10, \mathrm{Da}=1, \mathrm{Fr}=0.5, \mathrm{Pr}=10$ and $\phi=30^{\circ}$ are presented in Figure 3, showing a very good agreement.
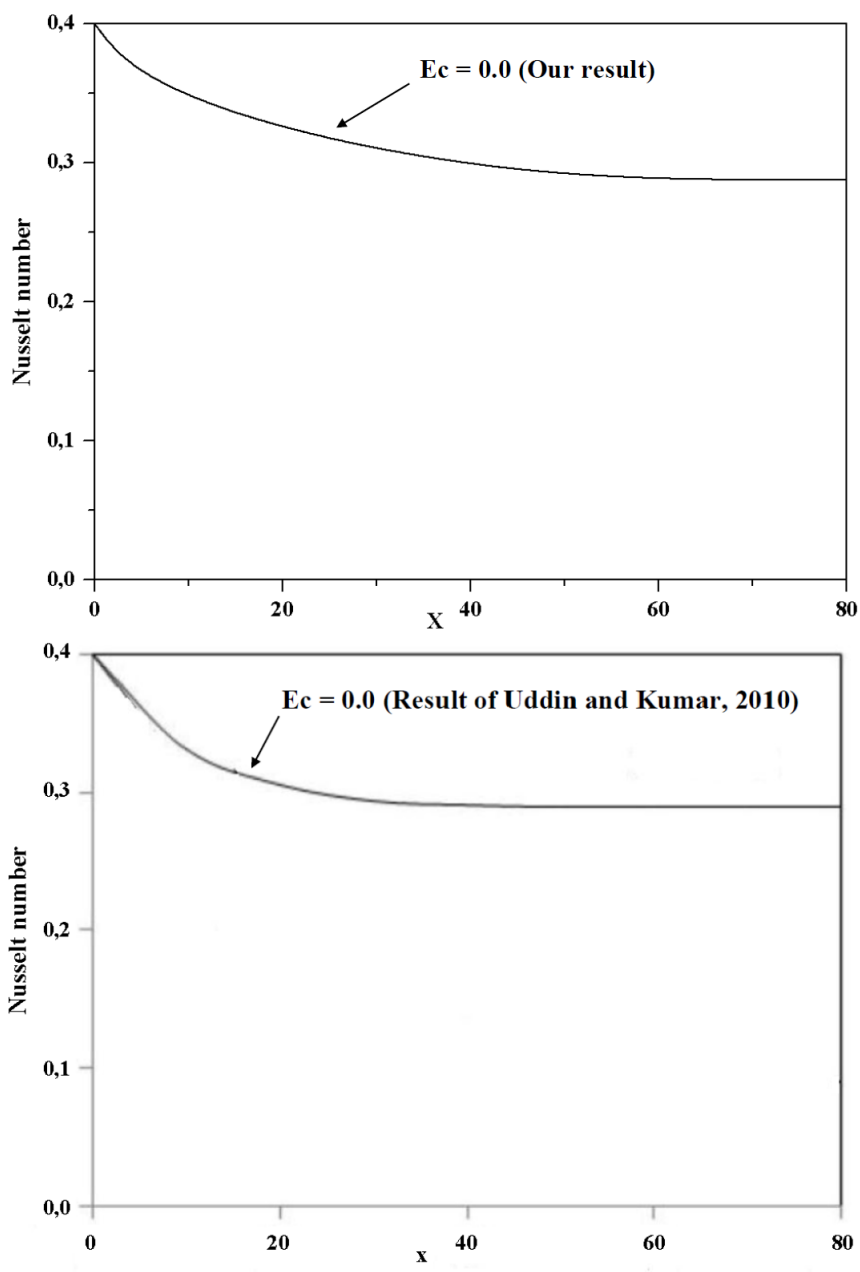

Fig. 3 Steady local Nusselt number as a function of $X$, for $E c=0.0$ with $F r=0.5, G r=1, \operatorname{Pr}=\operatorname{Re}=10, D a=1$ and $\phi=30^{\circ}$.

\subsection{Mesh-Size Effect on Numerical Solutions}

The effect of the size and number of nodes on the solution expressed by the average heat transfer at the plate surface is shown in figure 4 , for $R e=2, D a=0.1, F r=0.5, E c=0.05, \operatorname{Pr}=0.71$ and $\phi=30^{\circ}$. It is clear that the heat transfer is practically insensitive to the number of nodes from the grid $45 \times 45$. In the remainder of this work, we adopt, for reasons of compromise accuracy/computation time, the mesh of size $50 \times 50$

\subsection{Velocity Profiles and Streamlines}

Figure 5 shows the transient velocity profiles in the boundary layer area of an isothermal inclined plate injected in a saturated porous medium for different values of non-dimensional time. Here, it is clearly notable that the steady state is obtained at $t=250$, i.e. there is no major change in the velocity profiles after time $t=250$. Also, it is observed that, the velocity first increases near the plate and approaches to zero away from the plate,

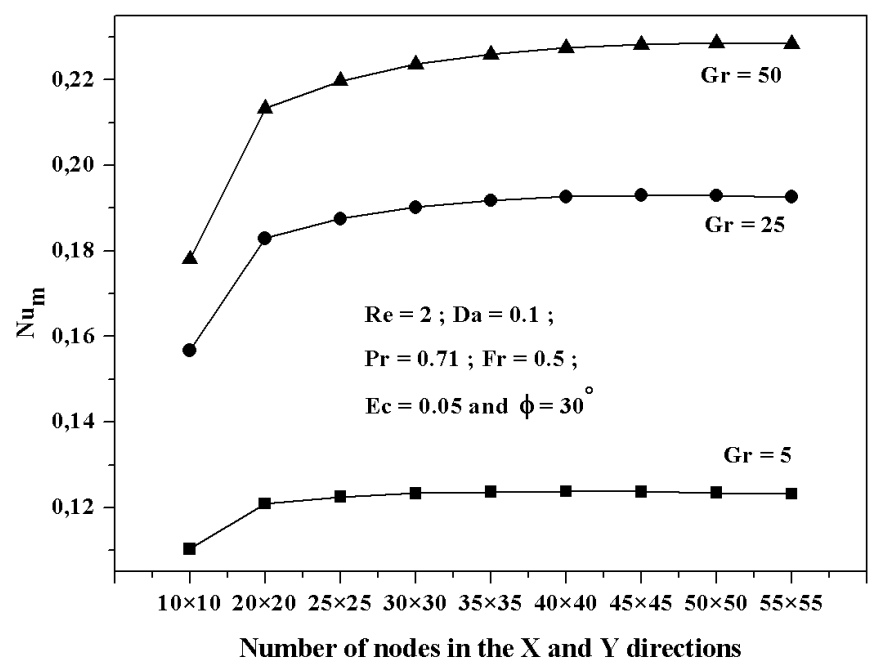

Fig. 4 Variation of $N u_{m}$ as a function to mesh size.

and consequentially the momentum boundary layer thickness increases with time. Figure 6 displays the steady state velocity profiles as a func-

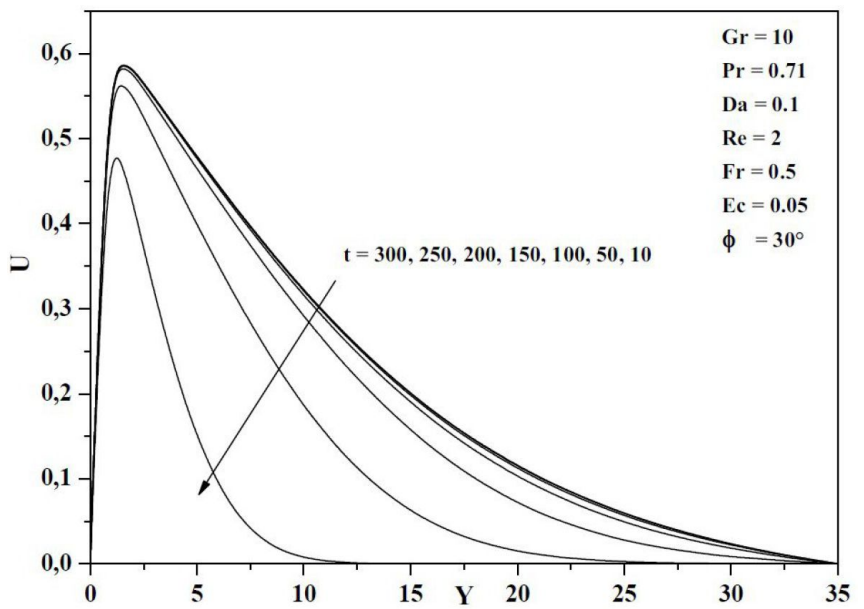

Fig. 5 Unsteady velocity profiles as a function of $\mathrm{Y}$ for various times at $X=50$.

tion of $Y$ at different $X$ position. From this figure, it is remarkable that the fluid activity at upper portion of the plate increases with increased $X$, which explains the widening of the dynamic boundary layer. The displayed figures 7 and 8 show the effect of Reynolds number on dimensionless streamlines of the velocity field over an isothermal and impermeable inclined plate $\left(\phi=30^{\circ}\right)$ in a saturated porous medium for $G r=10$, $\operatorname{Pr}=0.71, D a=0.1$ and $F r=0.5$ in the presence of viscous dissipation parameter $(E c=0.05)$. From the streamlines velocity, we notice that the importance of the inertia forces in the medium allows to accelerate the fluid flow in the boundary layer area. The displayed figures 9 and 10 show the effect of Darcy number on dimensionless streamlines of the velocity field over an isothermal and impermeable inclined plate $\left(\phi=30^{\circ}\right)$ in a saturated porous medium for $G r=10, \operatorname{Pr}=0.71$, $R e=2$ and $F r=0.5$ in the presence of viscous dissipation parameter $(E c=0.05)$. It is seen from these figures that, in the boundary layer area, the velocity is intensified in the case of $D a=10$ when compared to the case where $D a=0.05$. This is quite logical because the more $D a$ increases the more the permeability of the porous medium increases and consequently, the fluid flows faster in comparison to the porous medium at low Darcy number. 


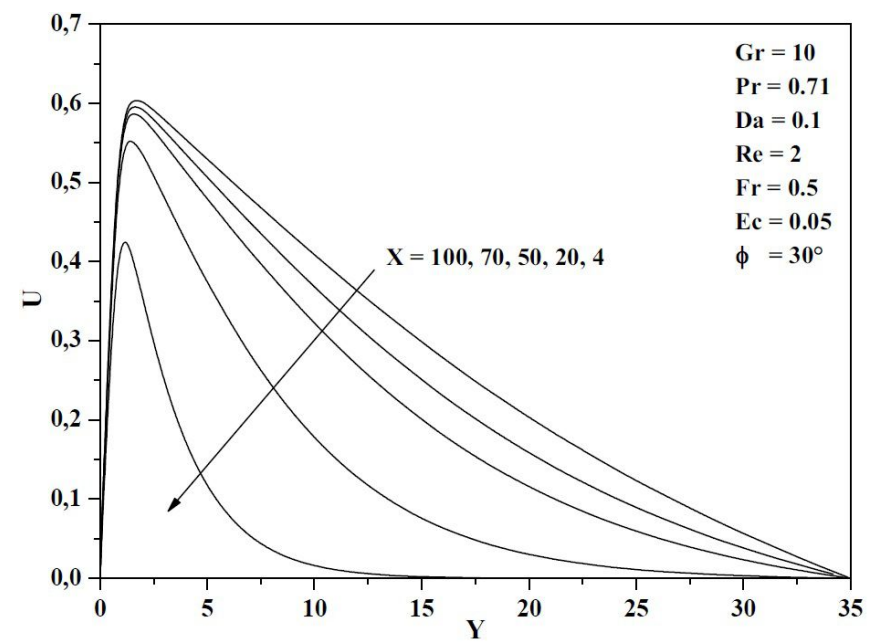

Fig. 6 Steady velocity profiles as a function of $\mathrm{Y}$ for selected position $X$.

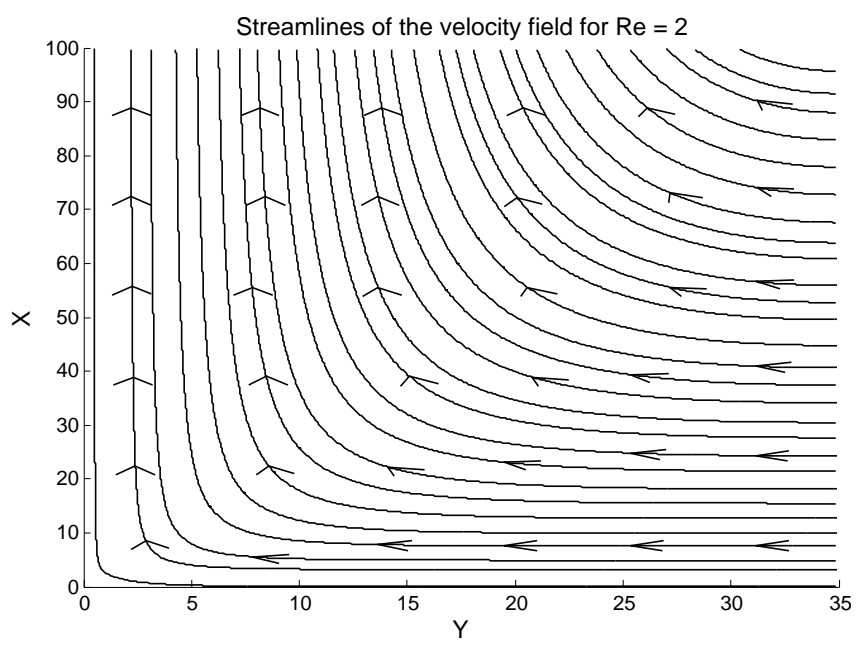

Fig. 7 Streamlines of dimensionless velocity field according to $\mathrm{X}$ and $\mathrm{Y}$ for $R e=2$.

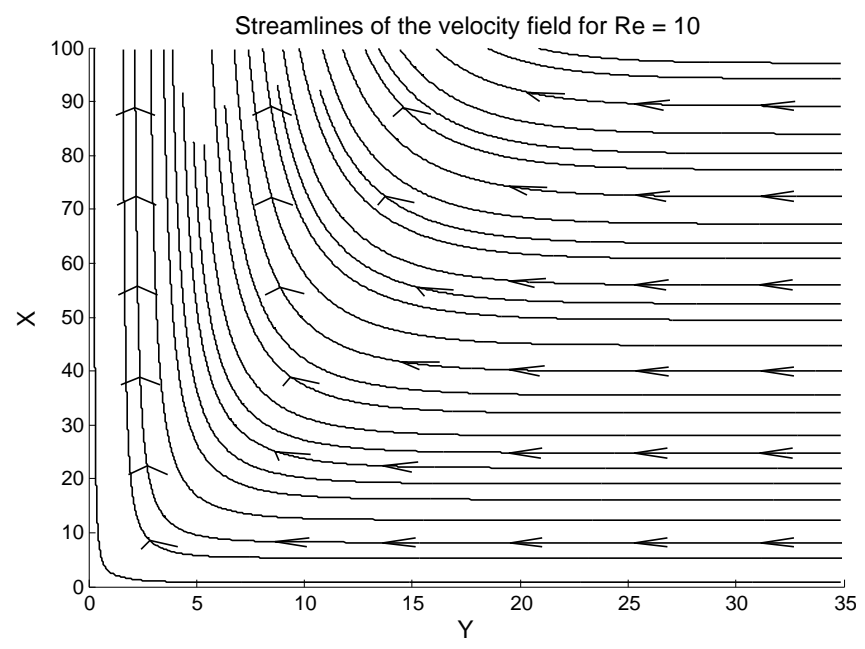

Fig. 8 Streamlines of dimensionless velocity field according to $\mathrm{X}$ and $\mathrm{Y}$ for $R e=10$.

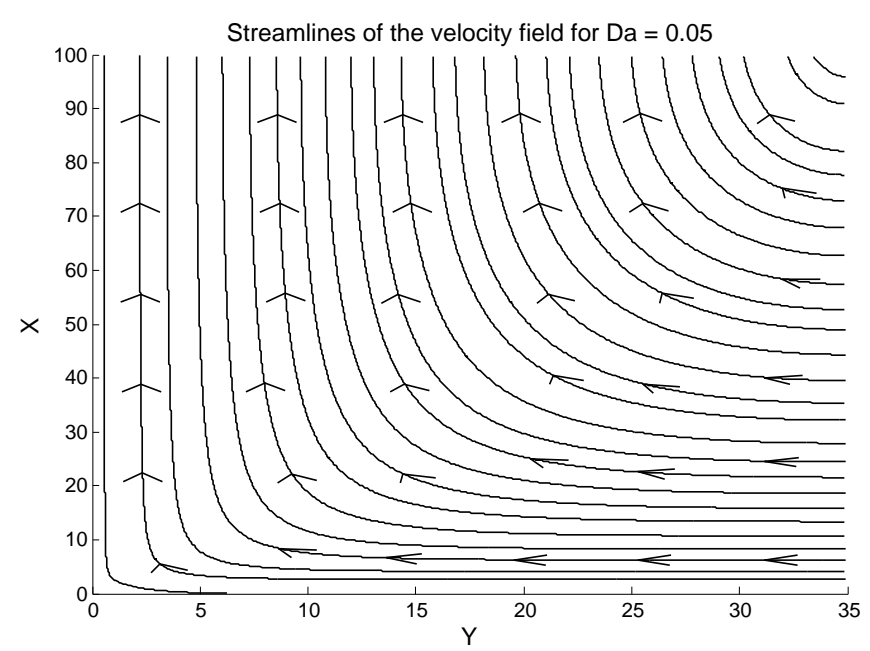

Fig. 9 Streamlines of dimensionless velocity field according to $\mathrm{X}$ and $\mathrm{Y}$ for $D a=0.05$.

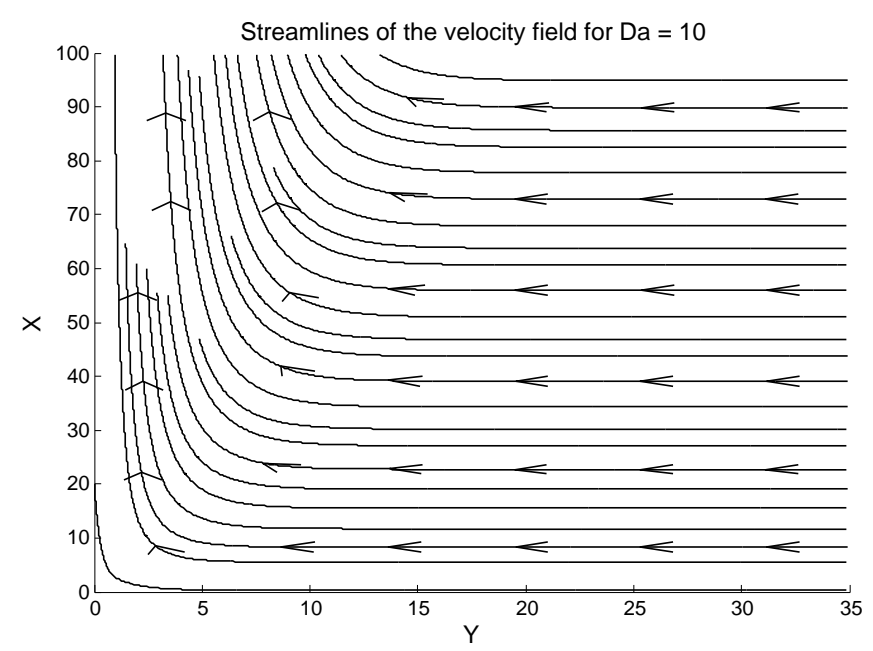

Fig. 10 Streamlines of dimensionless velocity field according to $\mathrm{X}$ and $\mathrm{Y}$ for $D a=10$.

\subsection{Isothermal Lines}

Figures 11 and 12 show for $G r=10, \operatorname{Pr}=0.71, R e=2, D a=$ $0.1, F r=0.5$ and $E c=0.05$, the isothermal lines distributions in the boundary layer area of an isothermal and impermeable inclined plate $\left(\phi=30^{\circ}\right)$ placed in a saturated porous medium, for selected values of the time $t=10$ and $t=300$, respectively. These figures show the development of the thermal boundary layer with the time $t$ up to $t=250$ (steady state start), where the latter is fully formed, which is consistent with the result found in Figure 5.

Figures 13 and 14 show for $G r=10, \operatorname{Pr}=0.71, \operatorname{Re}=2, F r=$ 0.5 and $E c=0.05$, the isothermal lines distributions in the boundary layer area of an isothermal and impermeable inclined plate $\left(\phi=30^{\circ}\right)$ embedded in a saturated porous medium, for selected values of the Darcy number $D a=0.05$ and $D a=3$, respectively. From these figures, we notice that the permeable porous medium promotes more the cooling in the boundary layer area, which explained the reduction in the thermal boundary layer thickness, unlike the case where the porous medium is less permeable.

Figures 15 and 16 show for $G r=10, P r=0.71, D a=0.1$, $R e=2$ and $E c=0.05$, the isothermal lines distributions in the boundary layer area of an isothermal and impermeable inclined plate $\left(\phi=30^{\circ}\right)$ 


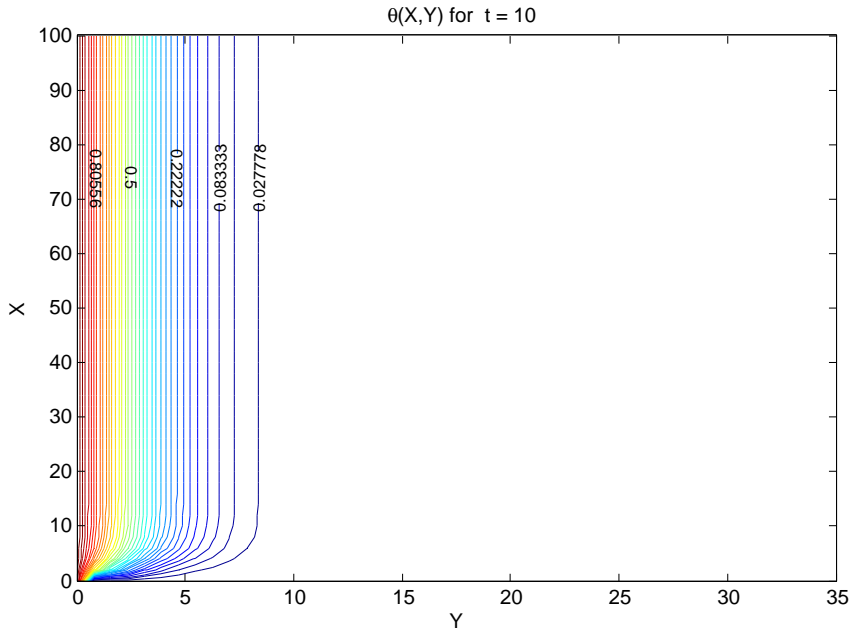

Fig. 11 Dimensionless isothermal lines according to $\mathrm{X}$ and $\mathrm{Y}$ at $t=10$.

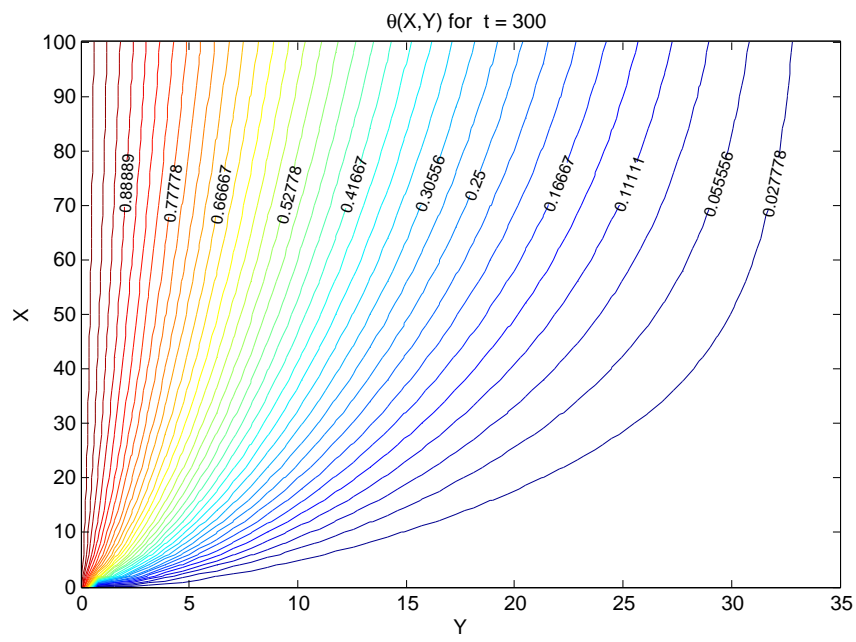

Fig. 12 Dimensionless isothermal lines according to $\mathrm{X}$ and $\mathrm{Y}$ at $t=300$.

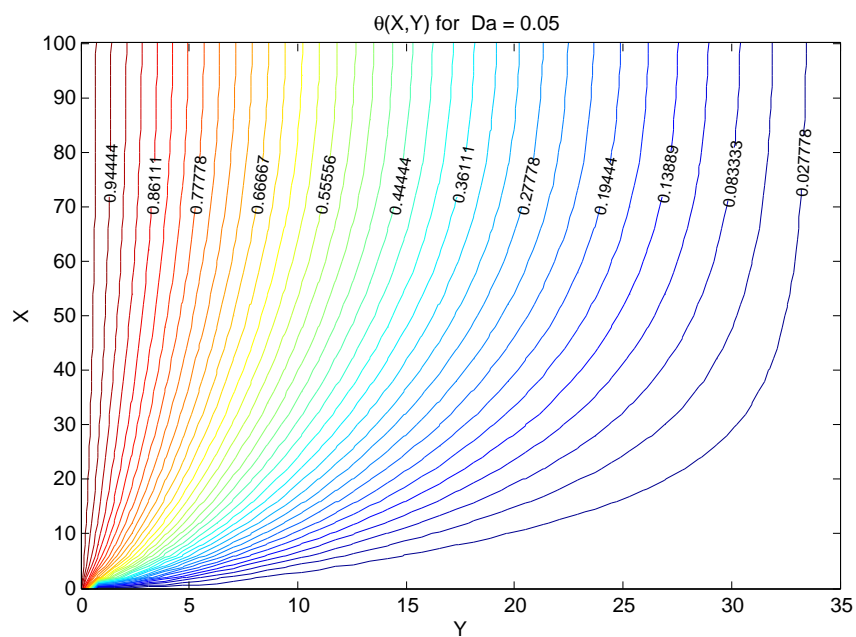

Fig. 13 Dimensionless isothermal lines according to $\mathrm{X}$ and $\mathrm{Y}$ for $\mathrm{Da}=$ 0.05 at $t=300$.

placed in a saturated porous medium, for selected values of Forchheimer number $F r=0$ and $F r=3$. Here, we notice that the increasing $F r$ values causes a strong increase in Forchheimer drag which decelerates

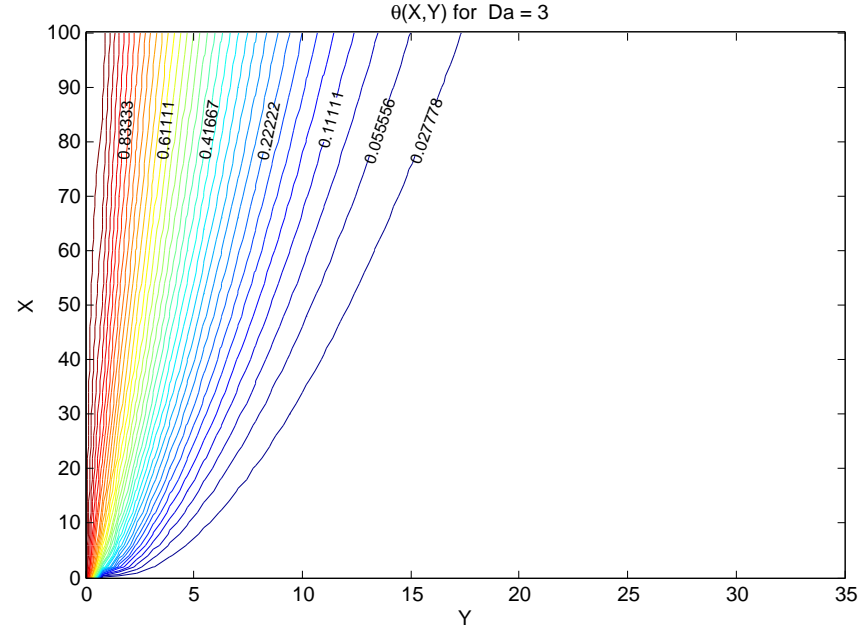

Fig. 14 Dimensionless isothermal lines according to $\mathrm{X}$ and $\mathrm{Y}$ for $D a=3$ at $t=300$

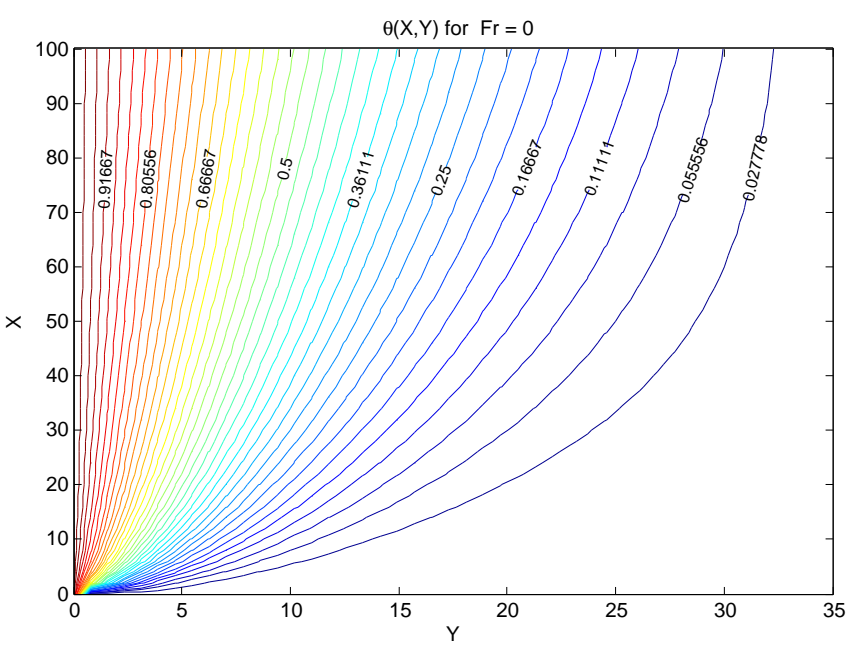

Fig. 15 Dimensionless isothermal lines according to $\mathrm{X}$ and $\mathrm{Y}$ for $\mathrm{Fr}=0$ at $t=300$.

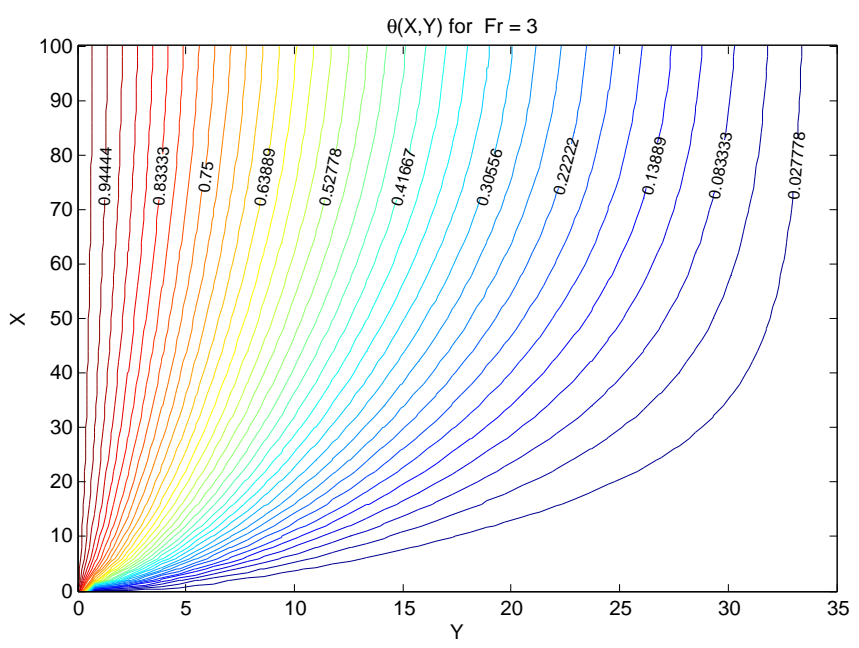

Fig. 16 Dimensionless isothermal lines according to $\mathrm{X}$ and $\mathrm{Y}$ for $\mathrm{Fr}=3$ at $t=300$. 


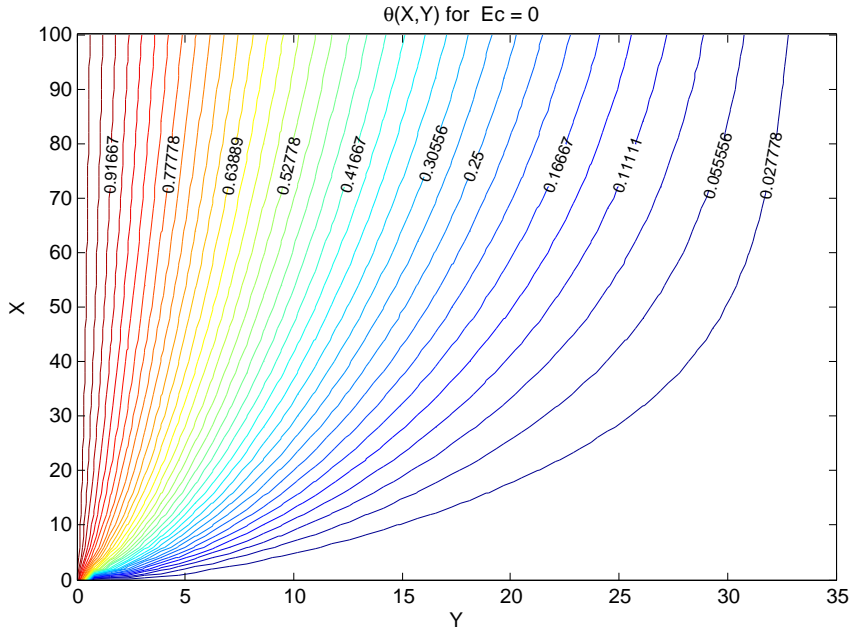

Fig. 17 Dimensionless isothermal lines according to $\mathrm{X}$ and $\mathrm{Y}$ for $E c=0$ at $t=300$.

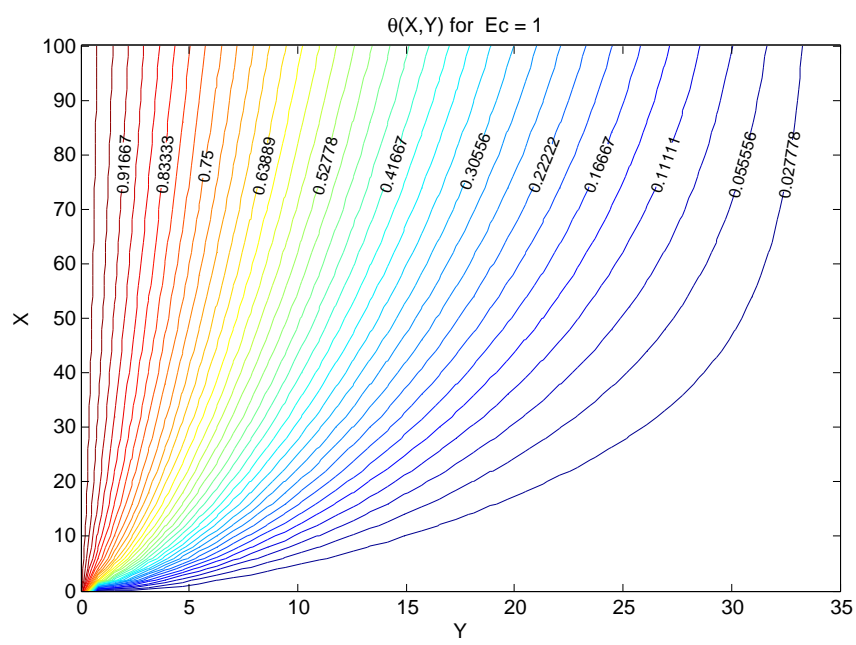

Fig. 18 Dimensionless isothermal lines according to $\mathrm{X}$ and $\mathrm{Y}$ at $E c=1$ at $t=300$.

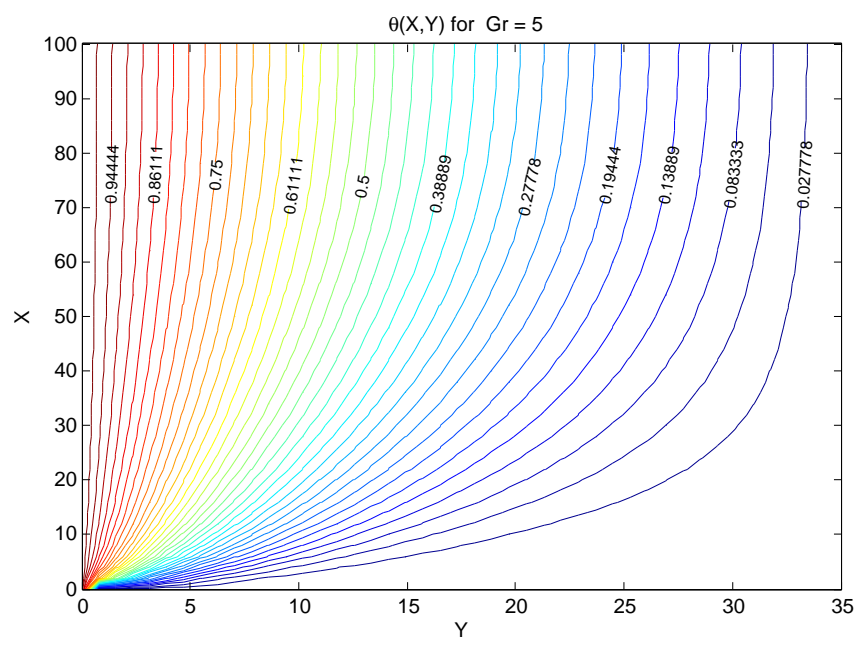

Fig. 19 Dimensionless isothermal lines according to $\mathrm{X}$ and $\mathrm{Y}$ at for $\mathrm{Gr}=$ 5 at $t=300$.

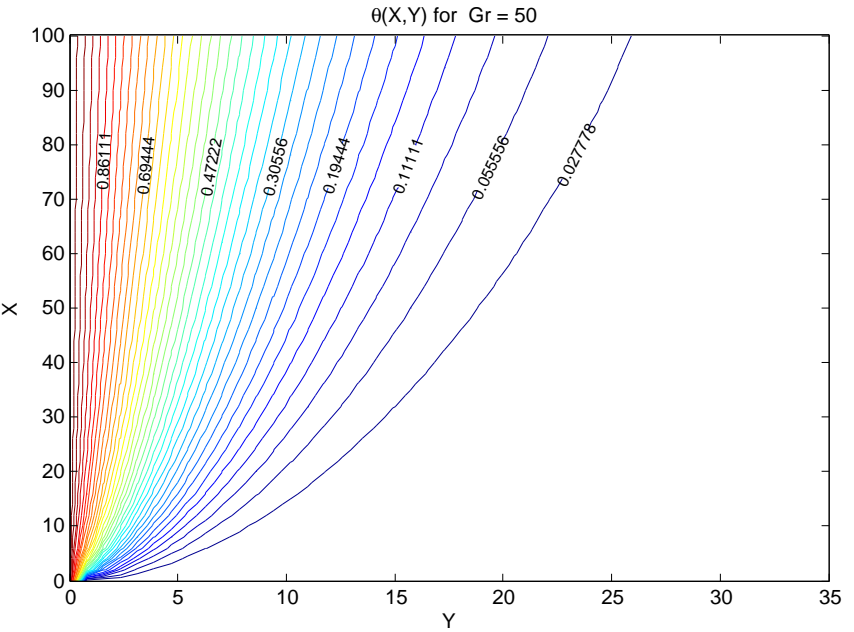

Fig. 20 Dimensionless isothermal lines according to $\mathrm{X}$ and $\mathrm{Y}$ for $\mathrm{Gr}=$ 50 at $t=300$.

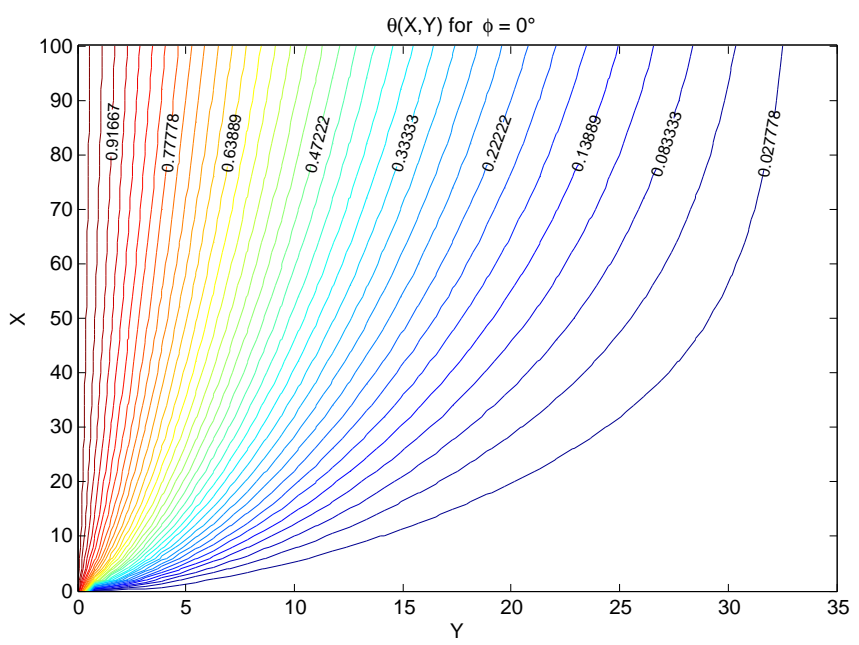

Fig. 21 Dimensionless isothermal lines according to $\mathrm{X}$ and $\mathrm{Y}$ for $\phi=0^{\circ}$ at $t=300$.

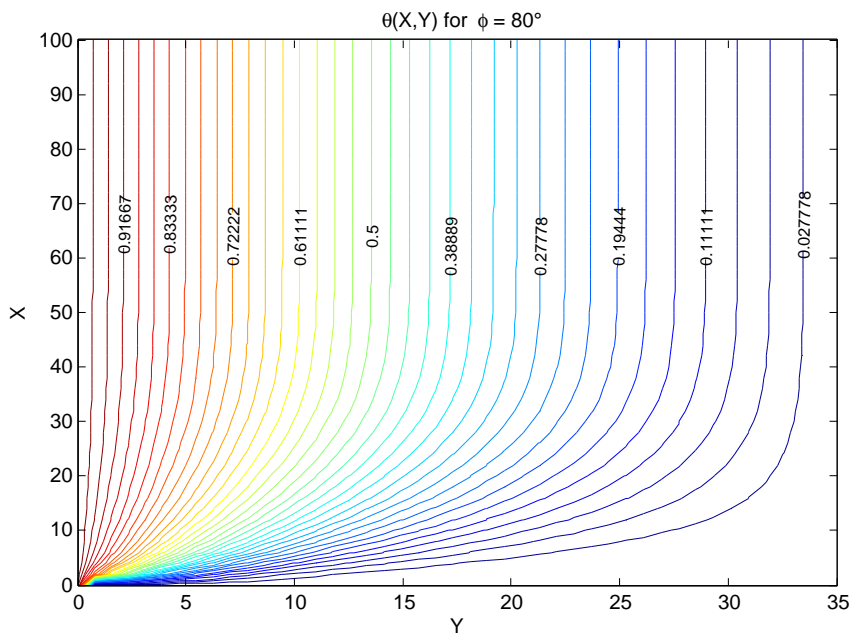

Fig. 22 Dimensionless isothermal lines according to $\mathrm{X}$ and $\mathrm{Y}$ for $\phi=80^{\circ}$ at $t=300$. 
the flow i.e. reduces velocities, which translates to a slight increase in temperature.

Figures 17 and 18 show for $G r=10, P r=0.71, D a=0.1$, $R e=2$ and $F r=0.5$, the isothermal lines distributions in the boundary layer area of an isothermal and impermeable inclined plate $\left(\phi=30^{\circ}\right)$ embedded in a saturated porous medium, for selected values of the Eckert number $E c=0$ and $E c=1$, indicate respectively without and with viscous dissipation. Here, the effect of viscous dissipation on free convection is to increase the energy, producing a rise in the temperature of the medium, which explains the widening of the thermal boundary layer thickness.

Figures 19 and 20 depict at $\mathrm{Pr}=0.71, \mathrm{Da}=0.1, \mathrm{Re}=2, \mathrm{Fr}=$ $0.5, E c=0.05$, the steady isothermal lines distributions in the boundary layer area of an isothermal and impermeable inclined plate $\left(\phi=30^{\circ}\right)$ inserted in a saturated porous medium, for selected values of the Grashof number $G r=5$ and $G r=50$ respectively. From these figures, we notice that the temperature decreases with increasing the Grashof number $G r$, and consequently leads to the reduction of the thermal boundary layer thickness. This can be justified by the importance of the buoyancy forces, which lead to a fast cooling around the plate.

Figures 21 and 22 show the isothermal lines distributions in the boundary layer area of an isothermal and impermeable plate placed in a saturated porous medium, for both position of the plate: vertical and inclined corresponding respectively to $\phi=0^{\circ}$ and $\phi=80^{\circ}$ at $G r=10$, $\operatorname{Pr}=0.71, D a=0.1, R e=2, F r=0.5$ and $E c=0.05$. From these figures, it is observed that, passing from the vertical to the horizontal position ( $\phi=90$ degree) of the plate, more heat is transferred to the porous medium, which leads to the widening of the thermal boundary layer thickness. Consequently, in the field of petroleum extraction by the thermal method, the vertical position of the used equipment is the most suitable for optimum oil extraction (high transfer rate).

\subsection{Local Heat Transfer Rate Profiles}

In figure 23, we present the variation of the heat transfer rate at the wall for several positions of the plate with $G r=10, \operatorname{Pr}=0.71, \operatorname{Re}=2$, $F r=0.5$ and $E c=0.05$ at $X=50$ for selected values of Dacy number $D a$. From this figure, it's concluded that passing from the vertical $(\phi=$ $\left.0^{\circ}\right)$ to the horizontal $\left(\phi=90^{\circ}\right)$ position of the plate, the heat transfer rate at the surface decreases independently of the Darcy number $D a$. In addition, the rate of heat transfer to the wall becomes important, when the porous medium is more permeable.

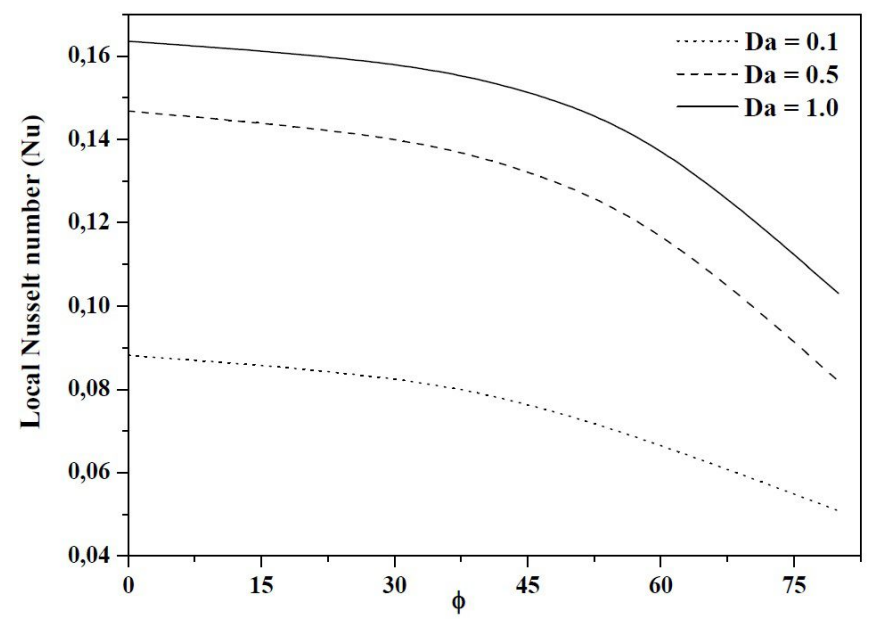

Fig. $23 \mathrm{Nu}$ profiles versus $\phi$ for selected values of $\mathrm{Da}$ at $X=50$ and $t=300$.

Steady state local Nusselt number profiles are plotted as a function of Forchheimer number $\mathrm{Fr}$ for an angle of inclination of the plate $\phi=30^{\circ}$

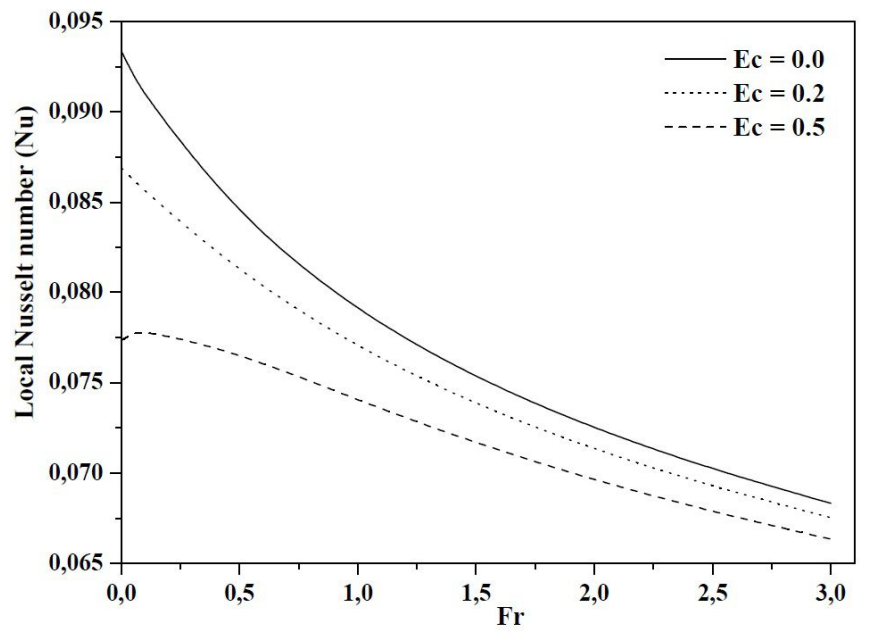

Fig. $24 \mathrm{Nu}$ profiles versus $\mathrm{Fr}$ for selected values of Ec at $X=50$ and $t=300$ for $\phi=30^{\circ}$.

with $G r=10, \operatorname{Pr}=0.71, D a=0.1, R e=2$ at $X=50$ for selected values of Eckert number $E c$ in figure 24. From this figure, it is clear that for $E c=0$ (without viscous dissipation) and for $E c=0.2$ or 0.5 (in the presence of viscous dissipation), the heat transfer rate at the surface of the plate decreases for all values of Forchheimer number Fr. Also, it's observed when the viscous dissipation increases, the heat transfer rate decreases.

The effects of the Grashof number and Reynolds number on the wall heat transfer rate at $\operatorname{Pr}=0.71, \mathrm{Da}=0.1, \mathrm{Fr}=0.5, \mathrm{Ec}=0.05$ and $X=50$ for an inclined isothermal plate $\left(\phi=30^{\circ}\right)$ embedded in a saturated porous medium in the presence of viscous dissipation, are plotted in figure 25 . Here, we notice that the buoyancy forces amplified the heat transfer rate at the wall for all values of the Reynolds number. Moreover, the importance of the inertia forces makes to amplify the heat transfer rate at the wall.

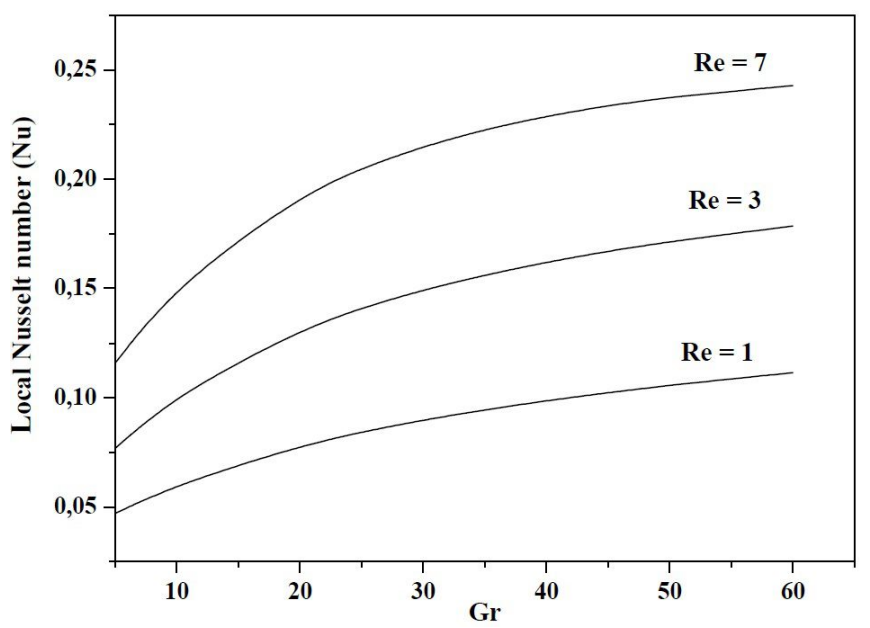

Fig. $25 \mathrm{Nu}$ profiles versus $\mathrm{Gr}$ for selected values of $\operatorname{Re}$ at $X=50$ and $t=300$ for $\phi=30^{\circ}$.

\section{CONCLUSION}

The finite difference method was used in this study to compute unsteady laminar free convection boundary layer flow around a multi-oriented plate embedded in a saturated porous medium with a Newtonian fluid in the presence of viscous dissipation. the Darcy-Brinkman-Forchheimer model was used to describe the flow field, taking into account the convective 
term. Numerical calculations were carried out for the various parameters entering into the problem. Velocity profiles, streamlines of the velocity field, isothermal lines distributions and the local Nusselt number profiles were shown graphically. The main conclusions of the current analysis are as follow:

1. The momentum and thermal boundary layer thicknesses increase with time.

2. The momentum boundary layer thickness and maximum velocity depends on the $\mathrm{X}$ position.

3. The importance of the buoyancy forces leads to a rapid cooling around the plate, and reduces the thermal boundary layer thickness.

4. The increase in the dissipation parameter $E c$ induces the increase in the fluid temperature.

5. Passing from the vertical to the horizontal position of the plate, more heat is transferred to the porous medium, which leads to the widening of the thermal boundary layer thickness.

6. An increase in the inertial forces leads to the increase of the heat transfer in the boundary layer area.

\section{NOMENCLATURE}

\begin{tabular}{|c|c|}
\hline$C_{p}$ & specific heat of fluid $\left(J K g^{-1} K^{-1}\right)$ \\
\hline$D a$ & Darcy number \\
\hline$E c$ & Eckert number \\
\hline$F$ & empirical constant \\
\hline$F r$ & inertia coefficient \\
\hline$g$ & gravitational acceleration $\left(\mathrm{m} \mathrm{s}^{-2}\right)$ \\
\hline$G r$ & Grashof number \\
\hline$H$ & height of the plate $(m)$ \\
\hline$i$ & index nodes in the $X$ - direction \\
\hline$j$ & index nodes in the $Y$ - direction \\
\hline$K$ & permeability of the porous medium $\left(\mathrm{m}^{2}\right)$ \\
\hline$k_{e}$ & effective thermal conductivity of porous medium \\
\hline$N$ & number of nodes contained on the $Y$ - direction \\
\hline$N u$ & local Nusselt number \\
\hline $\operatorname{Pr}$ & Prandlt number \\
\hline$R e$ & Reynolds number \\
\hline$T$ & fluid temperature $(K)$ \\
\hline$t^{\prime}$ & dimensional time \\
\hline$t$ & dimensionless time \\
\hline$u$ & dimensional velocity in $x$ - direction $\left(m s^{-1}\right)$ \\
\hline$U$ & dimensionless velocity in $X$ - direction \\
\hline$U_{r}$ & reference velocity $\left(\mathrm{m} \mathrm{s}^{-1}\right)$ \\
\hline$v$ & dimensional velocity in $y$ - direction $\left(m s^{-1}\right)$ \\
\hline$V$ & dimensionless velocity in $Y$ - direction \\
\hline$w$ & wall plate condition \\
\hline$x$ & dimensional coordinate along the plate $(m)$ \\
\hline$X$ & dimensionless coordinate along the plate \\
\hline$y$ & dimensional coordinate normal to the plate $(m)$ \\
\hline$Y$ & dimensionless coordinate normal to the plate \\
\hline$\Delta t$ & time step \\
\hline$\Delta X$ & space step in the $\mathrm{X}$-axis \\
\hline$\Delta Y$ & space step in the Y-axis \\
\hline \multicolumn{2}{|c|}{ Greek Symbols } \\
\hline$\alpha$ & thermal diffusivity $\left(m^{2} s^{-1}\right)$ \\
\hline$\alpha_{y}$ & distribution coefficient in the Y-axes \\
\hline$\beta$ & thermal expansion coefficient $\left(K^{-1}\right)$ \\
\hline$\varepsilon$ & porosity of porous medium \\
\hline$\nu$ & kinematic viscosity $\left(m^{2} s^{-1}\right)$ \\
\hline$\rho$ & fluid density $\left(\mathrm{Kg} \mathrm{m}^{-3}\right)$ \\
\hline$\theta$ & dimensionless temperature \\
\hline
\end{tabular}

$\phi \quad$ angle of inclination to the vertical direction

$\infty \quad$ infinity plate condition

\section{REFERENCES}

Achemlal, D., and Sriti, M., 2015, "Finite differences analysis on nonuniform mesh for free convection in a porous medium and comparison with similarity approach," Computational Thermal Sciences (CTS), 7(3), 231243.

http://dx.doi.org/10.1615/ComputThermalScien.2015013165.

Achemlal, D., Sriti, M., and El Haroui, M., 2014, "Numerical simulation of free convection flow in a saturated porous medium with finite differences method," Intermational Review of Mechanical engineering (IREME), 8(4).

Aldoss, T., Jarrah, M., and Al-Sha'Er, B., 1996, "Mixed convection from a vertical cylinder embedded in a porous medium: non-Darcy model," lnt J Heat Mass Transfer, 39(6), 1141-1148. https://dx.doi.org/10.1016/0017-9310(95)00211-1 .

Carnahan, B., Luther, H.A., and Wilkes, J.O., 1969, Applied Numerical Methods, John Wiley \& Sons, New York: Wiley - USA.

Chen, C., and Chen, C., 1990, "Non-Darcian mixed convection along a vertical plate embedded in a porous medium," Appl Math Modelling, 14(9), 482-488.

https://dx.doi.org/10.1016/0307-904x(90)90173-3.

Das, S., Jana, M., and Jana, N.R., 2013, "Effects of radiation and viscous dissipation on unsteady free convective flow past a moving vertical porous plate embedded in a porous medium," Communications in Applied Sciences, 1(1), 59-80.

El-Amin, M.F., and Ebrahiem, N.A., 2006, "Effect of viscous dissipation on unsteady free convection in a fluid past a vertical plate immersed in a porous medium," Transport in Porous Media, 64(1), 1-14.

http://dx.doi.org/10.1007/s11242-005-1126-6.

Flilihi, E., Sriti, M., Achemlal, D., and El Haroui, M., 2017, "Variable heat source and wall radiation effects on boundary layer convection from an inclined plate in non-darcian porous medium," Frontiers in Heat and Mass Transfer(FHMT), $\mathbf{9}(23)$.

http://dx.doi.org/10.5098/hmt.9.23.

Flilihi, E., Sriti, M., Achemlal, D., and El Haroui, M., 2019, "SemiAnalytical Prediction of Mixed Convection in Porous Medium Using Darcy-Brinkman Model," Journal of Engineering and Applied Sciences, 14(4), 1122-1129.

Ganesan, P., and Palani, G., 2004, "Finite difference analysis of unsteady natural convection mhd past an inclined plate with variable surface heat and mass flux," Int J Heat and Mass Transfer, 47(19-20), 4449-4457. https://dx.doi.org/10.1016/j.ijheatmasstransfer.2004.04.034.

Islam, M., Akter, F., and Islam, A., 2015, "Mass transfer flow through an inclined plate with porous medium." American Journal of Applied Mathematics, 3(5), 215-220.

https://dx.doi.org/10.11648/j.ajam.20150305.12.

Khanafer, K.M., and Chamkha, A.J., 1999, "Mixed convection flow in a lid-driven enclosure filled with a fluid-saturated porous medium." International Journal of Heat and Mass Transfer, 42(13), 2465-2481. https://dx.doi.org/10.1016/0017-9310(95)00211-1.

Mohiddin, S.G., Beg, O.A., and Varma, S.V.K., 2014, "Numerical study of free convective mhd flow past a vertical cone in non-darcian porous media," Theoretical and Applied Mechanics, 41(2), 119-140. http://dx.doi.org/10.2298/TAM1402119G. 
Mondal, R., Azad, M.A.K., Arifuzzaman, S., Hossain, K.E., and Ahmmed, S., 2016, "Unsteady free convective flow along a vertical porous plate with variable viscosity and thermal conductivity," , IOSR Journal of Mathematics (IOSR-JM), 12(1), 64-71.

Nield, D.A., and Bejan, A., 2017, Convection in porous media, 5th ed., Springer Science, New York - USA.

https://dx.doi.org/10.1007/978-3-319-49562-0.

Nield, D.A., and Simmons, C.T., 2018, "A Brief introduction to convection in porous media," Springer Nature.

Pop, I., and Herwig, H., 1990, "Transient mass transfer from an isothermal vertical flat plate embedded in porous medium," Int Comm Heat and Mass Transfer, 17(6), 813-821.

https://dx.doi.org/10.1016/0735-1933(90)90026-G.
Raptis, A., Singh, A.K., and D.Rai, K., 1987, "Finite difference analysis of unsteady free convective flow through a porous medium adjacent to a semi-infinite vertical plate," Mech Res Comm, 14(1), 9-16. https://dx.doi.org/10.1016/0093-6413(87)90004-8.

Udin, Z., and Kumar, M., 2010, "Unsteady free convection in a fluid past an inclined plate immersed in a porous medium," Computer Modelling and New Technologies, 14(3), 41-47.

Vafai, K., 2005, Handbook of porous media, 2nd ed., CCR Press Taylor\&Francis Group LLC, Boca Raton -USA.

Vasu, B., Ramachandra, P.V., and Bhaskar, R.N., 2011, "Radiation and mass transfer effects on transient free convection flow of a dissipative fluid past semi-infinite vertical plate with uniform heat and mass flux," Journal of Applied Fluid Mechanics, 4(1), 15-26. 